\title{
A treinta años de la guerra: las Islas Malvinas (Falkland) y los principios de derecho internacional
}

\author{
Thirty years after the war: the Malvinas (Falklands) \\ and principles of international law
}

\section{N. Alexander Aizenstatd*}

\section{Resumen}

En el $30^{\circ}$ aniversario de la Guerra de las Malvinas (Falkland)entre Argentina y el Reino Unido se presentan los hechos históricos más relevantes sobre las reclamaciones territoriales de las partes. Se analizan además la guerra de 1982 y la situación actual de las islas. Se estudian las acciones de las partes en relación con los principios del derecho internacional, entre ellos, la solución pacifica de las controversias, la prohibición de la amenaza y uso de la fuerza y la libre determinación de los pueblos. Se encuentra que ambas partes han faltado a sus obligaciones internacionales. Se concluye que la guerra no ha puesto fin a la controversia territorial y que esta puede ser resuelta por la negociación pero debe tomar en consideración los intereses de los habitantes de las islas.

Palabras clave: Malvinas (Falkland), derecho internacional, uso de la fuerza, libre determinación, solución de controversias

* Profesor de la Universidad Rafael Landivar, Guatemala. alexander@aizenstatd.com Recibido el 10 de abril de 2012; aceptado el 25 de septiembre de 2012. 


\section{Abstract}

On the 30th anniversary of the Falkland (Malvinas) war between Argentina and the United Kingdom, the most relevant historical facts regarding each party's territorial claims are presented. The war of 1982 and the present condition of the islands are studied. Parties' conduct in connection with principles of international law such as the peaceful settlement of disputes, the prohibition of the threat or use of force and the right to self-determination are examined. The paper finds that both parties have violated their international obligations and concludes that the war did not put an end to the territorial controversy and that this may be settled by negotiation but must take into account the interests of the inhabitants of the islands.

KEYwORDs: Falkland (Malvinas), international law, use of force, selfdetermination, dispute resolution. 


\section{INTRODUCCIÓN}

El año 2012 marca el trigésimo aniversario del conflicto armado entre el Reino Unido y Argentina por las Islas Malvinas (Falkland) ${ }^{1}$. Las islas consisten en un archipiélago situado en el Atlántico sur que es habitado por aproximadamente 3 mil personas (Comité Especial de Descolonización de las Naciones Unidas, 2010). Comprende principalmente la isla Gran Malvina (West Falkland), la isla Soledad (East Falkland) y cientos de islas menores y su respectivo espacio marítimo. La disputa abarca además a las Islas Georgia del Sur y Sandwich del Sur, que no están habitadas. Actualmente se encuentran bajo protección inglesa, que las considera un territorio británico de ultramar, pero son reclamadas como propias por Argentina. Una acción militar unilateral argentina para tomar el control de las islas en 1982 desencadenó una respuesta del Reino Unido que se tradujo en un conflicto armado entre ambas naciones, la muerte de casi un millar de personas y más de 1,800 heridos (Goñi, 2012).

La denominación utilizada para referirse a las Islas ya sea como Falkland o Malvinas es ampliamente considerada como una forma de evidenciar la postura de un autor sobre la legitimidad de los reclamos del Reino Unido o de Argentina a su respecto. En este trabajo utilizaré la denominación Malvinas (Falkland) debido a que es la forma más neutral de referirse al tema en español y es la adoptada por las Naciones Unidas. Además se usará de manera indistinta el término «las Islas».
A pesar de la relativamente discreta ubicación del archipiélago, gran parte de la comunidad de naciones y los más importantes organismos de las Naciones Unidas se han pronunciado respecto del diferendo entre Argentina y el Reino Unido ${ }^{2}$. En gran medida, pero con excepciones, los Estados latinoamericanos se han inclinado por la postura argentina; los Estados caribeños y ex colonias británicas han favorecido la perspectiva inglesa. Durante la Guerra de 1982, los actores más influyentes en el campo internacional rechazaron el uso de la fuerza por Argentina. A pesar de fijar su opinión sobre el uso de la fuerza, por lo general los Estados y las entidades internacionales han evitado pronunciarse sobre la legitimidad de las reclamaciones territoriales. Varios se han limitado a convocar a las partes a la negociación en aras de buscar una solución pacífica al conflicto, sin evaluar los méritos del título reclamado. En estos casos se ha hecho hincapié en el respeto a los principios de no agresión, la prohibición de la amenaza o el uso de la fuerza y la solución pacifica de controversias como valores esenciales del derecho internacional de conformidad con la Carta de las Naciones Unidas. Esta postura es común para este tipo de controversias. Tal y como señaló el internacionalista Thomas Franck, cuando los Estados no son parte directa en un conflicto tienden a evitar juicios de valor sobre las reclamaciones específicas en disputa y más bien buscan reafirmar

2 Véase nota 20 más adelante. 
los valores del derecho internacional en general (Franck, 1983: 116).

En el presente trabajo se expondrán los principales hechos históricos relacionados con la posesión de las Islas antes y después de la guerra. Se centrará la atención primordialmente en el análisis jurídico de los principios esenciales del derecho internacional aplicables a la resolución de esta disputa, que son la solución pacífica de las controversias, la prohibición de la amenaza o el uso de la fuerza y la libre determinación de los pueblos. Se explicará por qué la guerra no ha resuelto en forma definitiva la disputa territorial, señalando que las acciones de Argentina y el Reino Unido no han sido consecuentes con el derecho internacional y que toda resolución definitiva de la disputa debe tener en cuenta los derechos de los habitantes de las Islas. Finalmente, se propondrán fórmulas de solución teniendo presentes los cambios geopolíticos ocurridos en la región y los avances del derecho internacional a treinta años de la guerra.

\section{MARCO HISTÓRICO}

\subsection{El Nuevo Mundo y el legado de la administración aolonial}

Bastante se ha escrito ya sobre la historia de las Islas Malvinas (Falkland) y el conflicto armado de 1982 entre el Reino Unido y Argentina. De ahí que este trabajo se referirá a los hechos más relevantes sin pretender agotar los antecedentes históricos ${ }^{3}$. Además, se centrará la atención en los hechos de relevancia jurídica, sin hacer un análisis político. Hasta el momento, tanto el Reino Unido como Argentina reclaman la soberanía sobre el archipiélago, con base en escenarios que tuvieron lugar hace más de un siglo y en parte antes de que Argentina naciera a la vida independiente.

Tradicionalmente en el derecho internacional se han reconocido varias formas de adquisición de título soberano sobre territorios, entre las que destacan el descubrimiento, la ocupación, el acrecimiento, la cesión y la prescripción (Brownlie, 1999: 129-166) ${ }^{4}$. La postura inglesa en importante medida se basa en el descubrimiento, forma de adquisición de título sobre propiedad tradicionalmente aceptada conforme al derecho internacional, pero cuya importancia ha disminuido notablemente en el derecho internacional moderno. Sin embargo, la postura inglesa sostiene además la existencia de derechos adquiridos con base en la administración efectiva desde 1833 y los deseos de los habitantes actuales de las Islas. España, como poder

3 Véase entre otros: Goebel, 1950; Freedman y Gamba-Stonehouse, 1982; Vergara, Javier, 1992; Muñoz, 1966; Ferrer, 1984; Dolzer, 1993; Palacios, 1958; Boyson, 1924 y Welch, 1997: 483-507. Queda claro además que aún existen varios relatos históricos en disputa.

$4 \quad$ Esta breve descripción no pretende agotar la materia que es mucho más compleja y no incluye otras formas de adquirir propiedad reconocidas por el derecho internacional. 
colonial que antecedió a Argentina en este reclamo, también invocó el descubrimiento para basar su soberanía sobre el archipiélago, sumando a él la existencia de un decreto Papal que le otorgaba derechos sobre todo territorio en el Nuevo Mundo.

No existe información indubitable sobre el descubrimiento de las Islas Malvinas (Falkland), y lo más seguro es que la cuestión jamás sea finalmente resuelta. Algunos estudiosos sugieren que el primer europeo en reclamar su descubrimiento fue Américo Vespucio (Goebel, 1950: 3-4) $)^{5}$. Sin embargo, es posible que otros exploradores, aventureros y pobladores conocieran de la existencia de las Islas con anterioridad.

Además del descubrimiento, las pretensiones de soberanía sobre las Islas invocan la adquisición de título mediante la posesión pacífica por ocupación. Curiosamente, uno de los relatos más antiguos sobre la colonización de las Islas proviene de otro poder colonial, Francia. Ya en 1764 se autorizó una expedición oficial francesa para habitar las islas, esfuerzo que fue liderado por un joven oficial de apellido Bougainville con el apoyo de sus familiares provenientes de St. Malo en la Bretaña francesa. De estos primeros pobladores, conocidos por su gentilicio «les Malouines», derivó la denominación actual de las Malvinas empleada en español. Posteriormente, un destacamento militar inglés estableció

Argentina sostiene que fueron descubiertas por integrantes de la expedición de Magallanes, véase: Secretaria de Relaciones Exteriores de Argentina, 2012. una modesta instalación en la Isla en nombre del Rey Jorge III. España protestó ambas instalaciones en un territorio que consideraba propio. Eventualmente y luego de varias negociaciones, los franceses cedieron sus derechos a España. De ahí que algunos autores sostengan que una reclamación inglesa basada en el descubrimiento o posesión se debilita por una ocupación anterior francesa (Goebel, 1950).

Pocos años después, en 1770, el Reino español decidió desalojar por la fuerza el destacamento inglés y expulsar a los pobladores. El asunto se resolvió rápidamente por medio de negociaciones diplomáticas. En 1771 una pequeña fuerza militar inglesa estableció un campamento en Puerto Egmont, en la Isla Trinidad (Saunders) que ocupó por varios años y desocupó en 1774. Pero antes de retirarse, el comandante inglés dejó una inscripción en la estructura haciendo constar que no abandonaban sus derechos sobre el territorio. Este acto ha servido en parte para sustentar los reclamos actuales del Reino Unido. En 1777 España destruyó toda edificación inglesa incluyendo esa estructura militar.

Argentina argumenta también que el Armisticio y los acuerdos comerciales entre España y el Reino Unido que forman parte de los Tratados de Utrecht constituyen una renuncia inglesa sobre cualquier derecho sobre las Malvinas (Falkland). Los ingleses no comparten esta interpretación.

El el contexto histórico, la reclamación sobre las Islas involucra entonces 
a España, al Reino Unido y en menor medida a Francia. Argentina, luego de su independencia, sucedió al Reino español sustituyéndolo en sus derechos sobre el territorio. En América del Sur, basándose en el principio uti possidetis, desde 1810 se ha reconocido que el territorio de las naciones independientes conserva la demarcación colonial administrativa española (Crawford, 1979: 268 y Ratner, 1996: 590-595). El derecho internacional reconoce ampliamente la sucesión estatal derivada de la independencia de una colonia (International Law Association: 2008) ${ }^{6}$.

Luego de la independencia argentina, en 1829 el gobierno nacional creó una unidad administrativa de gobierno en las Islas. En 1833 el Reino Unido tomó el control de las Islas por la fuerza. Los pobladores y el gobierno argentino se retiraron bajo protesta (Waibel, 2011: 7). Desde entonces se inicia la reclamación de la Argentina independiente sobre el territorio con el argumento de la adquisición original española y la ocupación efectiva hasta 1833. Durante varias décadas ambos países llevaron a cabo negociaciones sin que el tema de la soberanía sobre las islas se resolviera de manera definitiva. Luego, en 1982, Argentina acudió a la opción militar.

6 Véase también: Corte Internacional de Justicia, Caso Relativo a la Controversia Fronteriza (Burkina Faso contra la República de Mali). I.C.J. Reports 1986, parr. 23-24.

\subsection{La guerra por las Malvinas (Falkland)}

En la segunda mitad del siglo pasado y en cierta medida desde antes, se realizaron varios esfuerzos con el fin de establecer negociaciones a nivel diplomático entre Argentina y el Reino Unido para resolver el diferendo sobre las Malvinas (Falkland). En algunos casos contaron con la intervención de organismos internacionales, pero ninguno de ellos resultó en un acuerdo sobre los reclamos territoriales. En la segunda mitad del siglo pasado el gobierno argentino estimaba que los ingleses no tenían un interés serio en llegar a una solución que incluyera discusiones formales sobre la soberanía de las islas. El 1 de marzo de 1982 la cancillería argentina declaró que si no se arribaba a una solución pronta, se acudiría a "otros medios» (Reisman, 1983: 311). Al mes siguiente, el 2 abril de 1982 el gobierno argentino, en ese momento dirigido por una Junta Militar, ocupó por la fuerza las islas y desalojó a sus habitantes.

El objetivo de la acción militar era desarmar las bases militares inglesas en las Malvinas (Falkland) con estrictas órdenes de no ocasionar bajas (Welch, 1997: 491). La operación se realizó de manera eficiente y el único fallecido del enfrentamiento fue un argentino, el capitán Pedro Giachino. Los militares ingleses fueron enviados al Reino Unido de manera inmediata. Para el medio día del 2 de abril, los argentinos habían asumido el completo control militar. 
N. Alexander Aizenstatd • A treinta años de la guerra: las Islas Malvinas...

Originalmente el plan instaurado por el gobierno argentino consistía en expulsar a los ingleses y colocar a las islas bajo administración internacional, mientras se resolvían finalmente los reclamos territoriales. Se buscaba en todo caso la estrategia de "ocupar para negociar» (Comisión de Análisis y Evaluación de las Responsabilidades del Conflicto del Atlántico Sur, 1983: 36 y 58). Sin embargo, las autoridades, seguramente al ver la manifestación de fervor nacional interno a favor de la operación militar y la reclamación territorial, se apartaron del plan original. Declararon públicamente que las islas eran territorio soberano argentino y que jamás retirarían su presencia militar.

Las circunstancias que llevaron a estos eventos son también relevantes. En 1983 se cumplirían 150 años de la toma del control de las islas por el Reino Unido, de ahí que era una fecha importante en el imaginario colectivo argentino. Existía presión social interna que reclamaba ese territorio como propio. Una parte mayoritaria de la población argentina denunciaba la presencia británica como una desposesión injusta. De hecho, incluso algunos sectores que se oponían a la Junta Miliar celebraron la operación que retomó el control argentino de las islas como una reivindicación de los derechos nacionales. Era claro que para muchos argentinos la presencia inglesa de por sí constituía un acto de agresión continuada por más de un siglo. Además, estimaban que los ingleses no negociaban de buena fe en aras de llegar a una solución final en todos los aspectos del conflicto. De ahí que vieran estas infructuosas negociaciones como una contravención de la obligación de negociar recomendada por la Asamblea General de las Naciones Unidas desde al menos $1965^{7}$. El gobierno argentino consideraba que el tiempo transcurría en su contra y a favor de los ingleses. El control efectivo y continuado inglés podría perjudicar los reclamos argentinos de manera definitiva (Waibel, 2011: 7).

La perspectiva que tenían los ingleses de los acontecimientos era claramente diferente. Consideraron que la acción militar argentina fue una medida unilateral de agresión contraria a la prohibición internacional del uso de la fuerza, por lo tanto debía ser resistida militarmente. Para el Reino Unido era importante defender un territorio sobre el cual consideraba tener un legítimo título. Asimismo, le era relevante no sentar un precedente internacional de permisividad y defender la prohibición del uso de la fuerza como parte esencial del orden público internacional.

Las instituciones mundiales y regionales fueron insuficientes para evitar un conflicto armado. También merece análisis la posición de los Estados Unidos como poder hegemónico de la época en el continente, país que país procuró servir de mediador a través de esfuerzos realizados por el Secretario de Estado Alexander Haig. Pero Argentina había subestimado la afinidad entre Estados

UN Resolution 2065 (XX) Question of the Falkland Islands (Malvinas) 16 December 1965 . 
Unidos y los británicos. El Reino Unido había sido importante aliado de los Estados Unidos en casi todos los conflictos principales del último siglo, incluyendo las dos guerras mundiales. Según Churchill entre ambos países existe una «relación especial» (special relationship) (Louis y Bull, 1986). Argentina era un importante socio latinoamericano en su lucha anticomunista y un aliado de sus intereses en la región, pero no tenía el mismo grado de relevancia en la política norteamericana. Un conflicto entre ambos países no beneficiaba a los Estados Unidos. Pero era claro que en última instancia Washington no intervendría a favor de Argentina contra su aliado natural en Londres. De hecho Reagan y Thatcher ya estaban en comunicación directa sobre el tema desde antes de la medida militar argentina ${ }^{8}$.

La respuesta inglesa no se hizo esperar. La Primera Ministra Thatcher explicó que estaban "defendiendo su honor como nación, y principios de fundamental importancia para todo el mundo" (Thatcher, 1995: 173-185) . Las acciones incluyeron el uso de varios submarinos nucleares, bombarderos y aviones caza para los cuales su contraparte argentina no estaba preparada (Paul, 1994: 146-165). Finalmente, los

8 Telegrama entre Ronald Reagan y Margaret Thatcher. Liddell Hart Centre for Military Archives (King's College, London): Woolly Al Walks the Kitty Back (BBC TV/Brian Lapping Associates Programme Archive), 6/1: notes on interview with James Rentschler, 1991.<http://www. margaretthatcher.org> (5 Marzo 2012).

9 La traducción es propia. ingleses retomaron el control de las islas y el conflicto terminó con la rendición argentina el 14 de junio de 1982. En definitiva, se perdió casi un millar de vidas, mayoritariamente argentinas. Hubo además cuantiosas pérdidas económicas en ambos lados: se estima que la guerra costó al Reino Unido más de 2.6 mil millones de dólares (Franck, 1983: 109). Un legado adicional serían los miles de minas terrestres que aun hoy se encuentran activas en las islas.

Estos hechos lamentablemente enlutaron a ambas naciones y las alejaron de la mesa de negociaciones. Algunos criticaron al gobierno de Thatcher por la magnitud de su respuesta militar, tildándola de esfuerzo político que buscó apoyarse en la solidaridad patriótica para distraer a la opinión pública de los problemas nacionales. Otros la han llamado una cruzada para la defensa de principios del derecho internacional sin consideraciones pragmáticas (Franck, 1982: 109) ${ }^{10}$. La reacción militar no fue del todo esperada si se considera la poca importancia económica y geopolítica de la región. Incluso con el potencial descubrimiento de hidrocarburos y el hecho de que podía servir de base para un reclamo sobre la Antártida. El Reino Unido ya había perdido su título sobre posesiones coloniales aún más valiosas sin embarcarse en una guerra de estas dimensiones.

10 Franckseñala que más se habría logrado si lo gastado en la guerra se hubiese distribuido entre los pobladores, incluyendo esfuerzos para reubicarlos y dotarlos de generosas pensiones. 
Las críticas al gobierno argentino de la época han sido aún más severas. Para muchos la operación militar argentina era un mecanismo político para desviar la atención de las graves violaciones de los derechos humanos cometidas por el régimen militar, ahora ampliamente documentadas (Comisión Nacional sobre la Desaparición de Personas, 1986). Algunos autores, como Virginia Gamba-Stonehouse, sostienen que estas consideraciones políticas internas no tuvieron un papel primordial en la decisión de tomar el control de las islas (La Nación, 2012). Sin embargo, estas consideraciones no pueden abstraerse de las implicaciones de la guerra. La infame reputación del gobierno de esa época incidió notablemente en el escaso nivel de apoyo internacional que recibió. En ambos casos, y principalmente en el caso argentino, la distracción de los problemas nacionales fue un factor que incidió en la acción militar (Pickering y Kisangani, 2010: 477-493).

\subsection{La controversia territorial subsiste}

Desde el punto de vista jurídico los motivos que dieron origen a la guerra no afectaron la legitimidad de cualquier reclamo territorial en la actualidad. Las condenables violaciones de los derechos humanos cometidas por el régimen militar argentino tampoco debilitan sus actuales reclamaciones. Al efecto, como señala el Profesor Reisman en su estudio sobre el caso de las Malvinas
(Falkland) «en la mayoría de sistemas legales, la propiedad es del legítimo dueño, no de la persona más amable» (Reisman, 1983: 288) ${ }^{11}$.

La victoria militar inglesa y la rendición argentina tampoco resolvieron finalmente la controversia territorial. De acuerdo con el derecho internacional moderno la victoria militar no es una manera legítima de adquirir territorio. De igual forma, un resultado militar adverso para el Reino Unido no habría afectado el reclamo inglés sobre las islas. La fuerza solamente determinó la posesión de las islas: el reclamo subyacente sobre la propiedad persiste. La ocupación forzosa de cualquiera de las partes no podría servir para legitimar su título. El territorio se adquiere por medio de título legítimo y no por la fuerza. El territorio como botín de guerra o derecho de conquista es incompatible con la Carta de las Naciones Unidas (Korman, 2003). Ni la ocupación argentina ni la victoria inglesa constituyen fundamento jurídico en apoyo a sus reclamos territoriales. Independientemente de la victoria militar o de la posesión actual, el legítimo título debe comprobarse. Esto es esencial en un sistema internacional que busca promover la seguridad mundial con base en el derecho. Este solo puede comprobarse mediante una de las formas de adquirir territorio aceptadas por el ordenamiento internacional. De ahí que la guerra de las Malvinas (Falkland) no incide en los reclamos territoriales bajo

11 La traducción es propia. 
el derecho internacional, aunque ciertamente es relevante en las reducidas condiciones para el diálogo existentes desde entonces entre ambos países.

\subsection{Las Malvinas (Falkland) boy}

Actualmente el Reino Unido considera que las Islas son un territorio de ultramar y figuran en la lista de territorios no autónomos según el capitulo XI de la Carta de las Naciones Unidas. Argentina las reclama como propias. Los habitantes tienen sus propias autoridades e incluso una Constitución ${ }^{12}$, avalada por la Reina Isabel II, que establece el marco institucional para el gobierno local e incluye una moderna y extensa sección sobre derechos fundamentales. No por casualidad inicia en su primer artículo con el derecho a la libre determinación. El gobierno local cuenta, entre otros, con una Asamblea Legislativa democráticamente electa con capacidad para dictar leyes (arts. 26 y 37); una Corte Suprema de Justicia unipersonal (art. 86), y un Consejo Ejecutivo (art. 57). Sin embargo, esto no significa que los pobladores gocen de plena autonomía. El gobierno local cuenta además con un Gobernador con amplios poderes, designado por la Reina, que incluyen disolver el parlamento (art. 34.1), nombrar al único magistrado de la Corte Suprema de Justicia (art. 86) y en casos limitados, puede dictar leyes (art. 55).

En las últimas décadas los recursos naturales de las islas han desempeñado

12 The Falkland IslandsConstitutionOrder 2008 (5 Nov. 2008) un papel protagónico en la controversia. No es infrecuente que las partes en una disputa magnifiquen la importancia de aquello por lo cual discuten. Sin embargo, las islas albergan una rica biodiversidad marina, que incluye numerosas especies de aves, peces y ballenas. Además, contienen reservas importantes de fitoplancton marino. También se ha resaltado la presencia de posibles enormes reservas de hidrocarburos. Estas reservas ya eran conocidas desde antes de la guerra de 1982 (Comisión de Análisis y Evaluación de las Responsabilidades del Conflicto del Atlántico Sur, 1983: 2). Ahora, algunos estiman que en las islas hay más de 60 miles de millones de barriles de petróleo (Kozloff, 2010).De ser cierto, convertiría a la región en una de las reservas de petróleo más grandes del mundo (Romero, 2012). Para ponerlo en perspectiva, las reservas de Ghawar, en Arabia Saudita, ascienden a $80 \mathrm{mi}$ les de millones (Irvine, 2009). Esto ha generado expectativas sobre la posibilidad de acceder a estos recursos tanto en Argentina como en el Reino Unido. Los habitantes de las islas también tienen un incentivo para considerar la posibilidad de subsistir económicamente de manera independiente.

Varias entidades efectúan actividades de exploración de estos recursos en la zona. La realización de actividades petroleras en las islas ha sido objetada por Argentina. Considera que la explotación de recursos naturales en un área en disputa es incompatible con la obligación de resolver el diferendo. 
Además, la realización de actividades petroleras a grandes profundidades genera preocupación por sus posibles efectos en el medio ambiente. Ya en el año 1991 murieron más de 16 mil pingüinos de Magallanes en un solo incidente por la contaminación petrolera (Kozloff, 2010). Sumada a los recursos de las islas, su zona marítima es un lugar importante para el tráfico de buques comerciales. Incluso hacia 1980 más de 200 mil barcos surcaban sus aguas cada año (Comisión de Análisis y Evaluación de las Responsabilidades del Conflicto del Atlántico Sur. 1983: 2).

Actualmente, en el $30^{\circ}$ aniversario de la guerra la confrontación entre Londres y Buenos Aires ha aumentado de manera notable. El Reino Unido ha enviado a las islas un fuerte contingente armado que incluye submarinos de propulsión nuclear y a su más moderno buque de guerra, el destructor Dauntless (Harding, 2012). Incluso el Príncipe Guillermo, segundo en la sucesión del trono de Inglaterra, ha prestado servicio militar este año en las Malvinas (Falkland) (BBC Mundo, 2012). Argentina ha protestado, indicando que esto constituye una provocación.

En Argentina, la Ministra de Industria ha pedido a las empresas locales que eviten adquirir productos del Reino Unido (El Tribuno, 2012) ${ }^{13}$. También, al menos en un caso se ha impedido el ingreso a puertos argentinos a cruceros de turistas de visita a las islas (El Universal,

13 La Ministra de Industria de Argentina, Débora Giorgi, solicitó a las industrias nacionales no importar productos ingleses.
2012) ${ }^{14}$. Además, Argentina ha obtenido el respaldo de los miembros de Mercosur para impedir la recalada de buques con bandera de las Malvinas (Falklands) en los puertos de los Estados miembros ${ }^{15}$. Se teme que de aumentar la confrontación se impida que los vuelos semanales de Chile a las islas puedan sobrevolar el espacio aéreo argentino.

Argentina reclama que se retomen las negociaciones sobre el diferendo. El Reino Unido ha declarado que la soberanía sobre las islas no está en disputa y no será discutida (BBC News, 2012). Independientemente de la negativa a negociar, los reclamos de soberanía subsisten. La eventual solución del este asunto debe respetar los principios del derecho internacional por lo que, a continuación se explican aquellos que son más relevantes en la lucha por las Malvinas (Falkland).

14 El Gobierno Ushuaia en la Provincia de Tierra del Fuego, en Argentina, negó el paso de los buques «Star Princess» y «Adonia», propiedad de Carnival Corporation.

15 Declaración de los Estados Partes del Mercosur y Estados Asociados sobre Buques que Enarbolan la Bandera Ilegal de las Islas Malvinas, Montevideo 20 de diciembre de 2011. Adoptada en la XLII Reunión del Consejo del Mercado Común y Cumbre de Presidentes de Mercosur celebrada en Montevideo, Uruguay. 


\section{LOS PRINCIPIOS DE DERECHO} INTERNACIONAL APLICABLES AL CASO MALVinAS (FALKLAND)

\subsection{La solución pacifica de las controversias internacionales}

La obligación de aplicar medios para la solución pacífica de las controversias internacionales es un principio consagrado del derecho internacional. Los Estados deben resolver sus conflictos por medios pacíficos. Al efecto, la Carta de Naciones Unidas en su artículo 2(3) reconoce claramente este principio y establece que: «Los Miembros de la Organización arreglarán sus controversias internacionales por medios pacíficos de tal manera que no se pongan en peligro ni la paz y la seguridad internacionales ni la justicia».

El Art. 33(1) del mismo instrumento dispone además que:

«Las partes en una controversia cuya continuación sea susceptible de poner en peligro el mantenimiento de la paz y la seguridad internacionales tratarán de buscarle solución, ante todo mediante la negociación, la investigación, la mediación, la conciliación, el arbitraje, el arreglo judicial, el recurso a organismos o acuerdos regionales u otros medios pacíficos de su elección.

Aparte de la Carta de las Naciones Unidas, el principio es reconocido por otros instrumentos, tales como la Declaración de Manila ${ }^{16}$ y el principio

16 Aprobada por la Asamblea General de las Naciones Unidas, Res. 37/10, 15 de noviembre de 1982 .
V del Decálogo del Acta Final de Helsinki ${ }^{17}$. La resolución pacifica de las disputas es esencial dentro del orden público internacional para mantener la paz y la seguridad. De ahí que está claramente prohibido acudir a la fuerza para solucionar una controversia. La reclamación de ambas naciones sobre las Islas Malvinas (Falkland) es una disputa jurídica que debe resolverse de conformidad con este principio.

Cabe aclarar que este principio obliga a los Estados a resolver sus controversias sin acudir a la fuerza, pero los deja en completa libertad para seleccionar el método para cumplir este fin. La libertad de elección en este caso ha sido reconocida desde 1923 por la Corte Permanente de Justicia Internacional en su Opinión consultiva en el asunto del Estado internacional de Carelia Oriental ${ }^{18}$. Los Estados pueden acudir a la mediación, arbitraje, conciliación, negociación o cualquier otro mecanismo y en todo caso, actuar de buena fe cuando hayan elegido uno de estos métodos, evitando realizar acciones unilaterales que agraven el conflicto.

La comunidad internacional ha reiterado sostenidamente la necesidad de que el conflicto sobre las Malvinas ( $\mathrm{Fa}$ lkland) se resuelva de manera pacífica. Ya en 1965 la Asamblea General de las Naciones Unidas invitó al Reino Unido

17 Adoptado por la Conferencia de Seguridad y Cooperación en Europa, 1 de agosto de 1975.

18 Corte Permanente Internacional de Justicia. Estado de la Carelia Oriental. Opinión Consultiva P.C.IJ. Ser. B, No. 5, p.27 (1923). 
y a Argentina a resolver la cuestión Malvinas (Falkland) por medio de negociaciones pacíficas ${ }^{19}$. El tema también ha sido objeto de varias otras resoluciones de la Asamblea General ${ }^{20}$ y del Consejo de Seguridad según el artículo 33(2) de la Carta de Naciones Unidas ${ }^{21}$.

De acuerdo con el derecho internacional la ocupación militar de las Islas Malvinas (Falkland) en abril de 1982 por las fuerzas armadas argentinas debe considerarse una contravención al principio de solución pacífica de las controversias. Incluso cuando esa acción no incluyó la pérdida de vidas inglesas.

19 UN Resolution 2065 (XX) Question of the Falkland Islands (Malvinas) 16 December 1965.

20 UN Resolution 3160 (XXVIII) Question of the Falkland Islands (Malvinas) 14 December 1973; UN Resolution 31/49 Question of the Falkland Islands (Malvinas) 1 December 1976; UN Resolution $37 / 9$ Question of the Falkland Islands (Malvinas) 4 November 1982; UN Resolution 38/12 Question of the Falkland Islands (Malvinas) 16 November 1983; UN Resolution 39/06 Question of the Falklands Islands (Malvinas) 1 November 1984; UN Resolution 40/21 Question of the Falklands Islands (Malvinas) $27 \mathrm{No}$ vember 1985; UN Resolution 41/40 Question of the Falklands Islands (Malvinas) 25 November 1986; UN Resolution 42/19 Question of the Falklands Islands (Malvinas) 17 November 1987; UN Resolution 43/25 Question of the Falkland Islands (Malvinas) 7 November 1988.

21 Security Council Resolution 502 Question concerning the situation in the region of the Falkland Islands (Malvinas) 3 April 1982; UN Resolutions Security Council Resolution 505 Question concerning the situation in the region of the Falkland Islands (Malvinas) 26 May 1982.
La posición inglesa también debe de analizarse de acuerdo con este principio. El gobierno inglés se niega a discutir el tema de la soberanía (BBC News, 2012). Esta negativa contraviene el derecho internacional. La falta de negociaciones de buena fe sobre la disputa antes y después de la guerra y el hecho de que ella se centre principalmente en la reclamación sobre las islas es contrario al espíritu y fin de los artículos 2(3) y 33(1) de la Carta de las Naciones Unidas. Cabe destacar sin embargo que en algunas oportunidades el gobierno inglés ofreció el empleo de métodos de solución de conflictos que no fueron aceptados por Argentina.

La reacción militar inglesa a la ocupación de 1982 también pudo evitarse. La opción militar para retomar el control de las islas no era indispensable, en especial considerando que resultaría en la pérdida de vidas. La vida o integridad física de sus ciudadanos o la de los pobladores de las Malvinas (Falkland) no se encontraba en riesgo inminente y volver al status ex ante costó casi un millar de vidas. Es claro que desde el punto de vista del Reino Unido esa intervención era aceptable y constituía un caso de legítima defensa de su territorio ante una agresión. Pero para Argentina la ocupación podía defenderse sosteniendo que consistía en la recuperación de un territorio usurpado por el Reino Unido. En 1833 el Reino Unido había utilizado la fuerza para desalojar a los habitantes argentinos de las islas. En 1982 debió buscarse una solución pacífica al conflicto. La posición inglesa 
pudo esperar, ciertamente algunos meses, que las instituciones internacionales cumplieran un papel determinante en la solución del conflicto; Argentina lo había hecho por más de un siglo.

El fiel cumplimiento de la obligación de resolver las controversias por medios pacíficos también incluye la prohibición de adoptar medidas unilaterales que agraven la disputa o pongan en riesgo su posible solución. Cabe destacar que el otorgamiento de concesiones para la explotación de recursos minerales o hidrocarburos en un área bajo disputa resulta contrario al objeto y fin de este principio. Además genera genuinas preocupaciones en materia ambiental cerca de la costa argentina continental. Este aspecto ya ha sido discutido por tribunales internacionales en la región (Aizenstatd, 2011). Los Estados deben evitar tomar medidas unilaterales que hagan más difícil la solución de la controversia.

\subsection{La probibición de la amenaza o el uso de la fuerza}

La prohibición de la amenaza o el uso de la fuerza es un principio consagrado del derecho internacional moderno. Implica que los Estados no pueden acudir a la fuerza o a la amenaza de la misma salvo en el caso de legitima defensa o con la aprobación del Consejo de Seguridad (Bolaños, 2009: 174). El Artículo 2(4) de la Carta de Naciones Unidas recoge este principio expresamente y prohíbe la agresión. La Organización de las Naciones Unidas se creó precisamente para "preservar a las generaciones venideras del flagelo de la guerra». Por lo tanto, es claro que la necesidad de aplicar este principio surge de la experiencia de la posguerra y de la necesidad de evitar los conflictos armados y sus lamentables consecuencias. El principio además se destaca en la Declaración Relativa a los Principios de Derecho Internacional referentes a las Relaciones de Amistad ${ }^{22}$. Su importancia en el derecho internacional es tan fundamental que ha sido reconocido como parte del ius cogens, obligatorio para todas las naciones (Pastor Ridruejo, 2009: 618). Esta calidad ha sido reiterada por la Corte Internacional de Justicia ${ }^{23}$.

Aunque no tenga implicaciones directas en la legitimidad del reclamo territorial subyacente, es importante analizar la conformidad de las acciones argentinas e inglesas con el derecho internacional. Una controversia territorial no justifica un acto de agresión. De ahí que los Estados incurran en responsabilidad internacional por la amenaza o uso de la fuerza en áreas en disputa ${ }^{24}$. Es claro que para Argentina la ocupación de 1982 fue un acto de defensa de

22 Principio 1, Resolución 2625 (XXV) de la Asamblea General de Naciones Unidas, 24 de Octubre de 1970.

23 Corte Internacional de Justicia. Caso Relativo a las Actividades Militares y Paramilitares en Nicaragua y Contra Nicaragua (Nicaragua contra los Estados Unidos de América), I.C.J. Reports 1986 p. 190.

24 Véase: Eritrea-Ethiopia Claims Commission, Partial Award, Jus ad Bellum: Ethiopia's Claims 1-8 (19 Dec. 2005),45 I.L.M. p. 430 (2006), parra. 10 y Aizenstatd, 2011. 
la integridad territorial. Actos similares habían sido tolerados por la comunidad internacional en otros casos, entre ellos Goa, posesión portuguesa tomada por la fuerza por India en 1961. Incluso el control del Reino Unido sobre las islas había surgido por el uso de la fuerza en 1833. Sin embargo, la tolerancia no hace que sean conformes con las obligaciones internacionales aplicables. De acuerdo con los principios de la Carta de las Naciones Unidas, las partes deben resolver sus controversias por medios pacíficos.

De acuerdo con la prohibición del uso o amenaza del uso de la fuerza también es relevante la conducta del Estado que tiene el control sobre un área en disputa. Además es aplicable al espacio marítimo pertinente. En el caso Nicaragua la Corte Internacional de Justicia destacó que las formas menos graves de amenaza del uso de la fuerza también constituyen una violación del derecho internacional ${ }^{25}$. Tan solo la amenaza es una contravención del derecho internaciona ${ }^{26}$. Como ejemplo, en el caso del diferendo marítimo entre Guyana y Suriname, un tribunal arbitral sostuvo que los requisitos para que se violara este principio eran bajos. En esa oportunidad un oficial surinamés

25 Corte Internacional de Justicia. Caso Relativo a las Actividades Militares y Paramilitares en Nicaragua y Contra Nicaragua, (Fondo) I.C.J. Reports 1986, p. 14, at parra. 190.

26 Véase Corte Internacional de Justicia. Legalidad de la Amenaza o Uso de Armas Nucleares. Opinión Consultiva. I.C.J. Reports 1996. advirtió al titular de una licencia de explotación de hidrocarburos concedida por Guyana en la zona en disputa que si no se retiraba las "consecuencias serían suyas». El tribunal sostuvo que este acto constituía una amenaza del uso de la fuerza y una contravención del artículo 279 de la Convención de las Naciones Unidas sobre el Derecho del Mar (Aizenstatd, 2011).

Recientemente Argentina ha protestado la presencia militar inglesa en las islas ${ }^{27}$. Según algunos informes, en la zona en disputa se encuentran los más modernos buques de la armada inglesa, submarinos nucleares y otros instrumentos de combate ${ }^{28}$, lo que Argentina denuncia como un acto de provocación, que además contraviene el Tratado de Tlatelolco para la Proscripción de las Armas Nucleares en América Latina y el Caribe. Este instrumento, suscrito por ambos países, prohíbe la presencia, amenaza o uso de armamento nuclear en Latinoamérica $^{29}$. Al efecto cabe señalar que una presencia militar de esta magnitud es de por sí lamentable. Todo ejercicio militar conlleva una demostración de fuerza, aunque esto no implica que sea contrario al derecho internacional. Bajo el inusual estándar del laudo en

27 Carta del 10 de febrero de 2012 dirigida al Secretario General por el Encargado de Negocios a.i. de la Misión Permanente de Argentina ante las Naciones Unidaso. Doc. A/66/696-S/2012/86.

28 Presentación del Gobierno Argentino ante las Naciones Unidas, 10 febrero 2012.

29 El Reino Unido suscribió el Protocolo Adicional al Tratado de Tlatelolco. 
el caso de Guyana contra Suriname podrían darse las circunstancias para que sea considerado como una amenaza de uso de la fuerza, principalmente porque es desproporcionada para el objetivo que se busca proteger y porque puede ocasionar una escalada del conflicto. Pero la presencia de un submarino de propulsión nuclear naval no constituye en sí una violación al Tratado. Todo esto según su artículo 5 , salvo que además cuente con armamento nuclear. Esta circunstancia ha sido negada por el Reino Unido que guarda una comprensible discreción sobre su arsenal nuclear. Sin embargo, si ha llevado armamento nuclear al Atlántico sur estaría claramente contraviniendo sus obligaciones internacionales. Además, contravendría el implícito «tabú nuclear» sobre la amenaza del uso de armas nucleares contra Estados que no las poseen. En todo caso, no existe motivo razonable para presumir que el Reino Unido estaría dispuesto a emplear ese tipo de armamento en esta situación.

\subsection{La libre determinación de los pueblos}

El Reino Unido fue un imperio colonizador, que con el tiempo ha ido cediendo voluntariamente algunos de sus territorios de ultramar o los ha perdido por la fuerza. Las Islas Malvinas (Falkland) han sido declaradas territorio bajo examen del Comité Especial de Descolonización de las Naciones
Unidas $^{30}$. Sin embargo, en algunos sentidos el caso se distingue de la acepción tradicional de colonia. Los pobladores actuales son preponderadamente afines al Reino Unido, en especial porque este ha tenido el control efectivo de la isla desde 1833, cuando desalojó a los pobladores argentinos. En su mayoría descienden de los primeros colonos británicos. Por lo tanto, a diferencia de otros casos típicos de colonialismo, no existe una población oprimida que reclame; el papel del principio de libre determinación juega entonces un papel que merece particular atención.

De acuerdo con el derecho internacional, la libre determinación debe de entenderse como el «derecho de grupos nacionales cohesionados a escoger por sí mismos una forma de organización política y su relación a otros grupos» (Brownlie, 1999: 599). Faculta a los integrantes de un grupo para determinar su propio estatus político, participar en sus instituciones y contribuir a su propio desarrollo económico, social y cultural. Tradicionalmente se ha invocado cuando a un grupo se le niega el derecho a participar en su propio gobierno sin injerencia externa o cuando a un grupo racial nacional no se le conceden las mismas oportunidades que los demás para hacerlo. Este principio,

30 Véase: Informe del Comité Especial encargado de examinar la situación respecto de la aplicación de la Declaración sobre la concesión de la independencia a los países y pueblos coloniales sobre la labor realizada en 2011. UN Doc. A/66/23, 6 de Julio del 2011, p. 28. 
que es además un derecho humano, es reconocido en varios instrumentos internacionales. En su artículo 2 (1) la Carta de las Naciones Unidas señala que uno de sus objetivos principales es promoverlo; por su parte, el artículo 55 pone de relieve la obligación de respetarlo. Asimismo, el Pacto Internacional de Derechos Civiles y Políticos en su primer artículo señalaque: «Todos los pueblos tienen el derecho de libre determinación. En virtud de este derecho establecen libremente su condición política y proveen asimismo a su desarrollo económico, social y cultural» ${ }^{31}$.

La Declaración Relativa a los Principios de Derecho Internacional Referentes a las Relaciones de Amistad también reconoce este derecho. Resulta así que el derecho internacional reconoce ampliamente el derecho a la libre determinación de los pueblos. ${ }^{32}$ Aunque históricamente no había tenido un papel protagónico en las discusiones sobre las Malvinas (Falkland), en el último tiempo ha adquirido importancia debido a que ha sido invocado por el gobierno británico para señalar que cualquier resolución al respecto debe tomar en cuenta los derechos y opiniones de

31 Pacto Internacional de Derechos Civiles y Políticos. Adoptado por la Asamblea General de las Naciones Unidas UN RES 2200 A (XXI) del 16 de diciembre de 1966.

32 Para un análisis más detallado sobre este derecho véase: Secretario General, Naciones Unidas. Informe: Realización universal del derecho de los pueblos a la libre determinación. UN Doc. A/61/333 del 12 de septiembre del 2006; Quane, 1998: 537572; y Crawford, 2001: 7-67. los habitantes. El argumento resulta políticamente ventajoso si se considera la mayor afinidad con el Reino Unido de los pobladores de las islas y es de utilidad para resistir las pretensiones argentinas ya que cabe prever que de ser consultados muy probablemente se opondrían a la soberanía argentina. En marzo de 2013 debería realizarse un referendum que presumiblemente dará por resultado una mayor preferencia por el Reino Unido, de ahí que Argentina lo rechace. La posición ha sido irónicamente catalogada por el Primer Ministro David Cameron como un acto de colonialismo argentino (BBC News, 2012). Sin embargo, más allá de los beneficios políticos que pueda acarrear este argumento, es posible dudar de la sinceridad inglesa cuando sostiene que la libre determinación es un principio del derecho internacional, puesto que tradicionalmente lo ha negado a sus antiguas posesiones coloniales y lo esgrime precisamente ahora en relación con Gibraltar y las Malvinas (Falkland) (Brownlie, 1999: 601). Sin embargo, ello no impide que en este caso haya que analizarlo.

Algunos defensores de la postura argentina han rechazado la aplicabilidad del principio a este caso. En especial, se oponen a que los habitantes de las islas sean caracterizados como un pueblo cohesionado. Sostienen que su presencia equivale a la de una población trasplantada desde 1833. Al efecto, los más críticos han comparado el caso «como pretender que los habitantes del barrio chino de Belgrano, en Buenos 
Aires, quieran responder políticamente a Beijing» (Ramos Horta, 2012). Considero que la postura inglesa no puede descartarse con tanta levedad. Los habitantes de las islas las han ocupado durante casi dos siglos, sin injerencia o control de las autoridades argentinas y tienen características lingüísticas y culturales propias distintas de aquellas de los ingleses. Si bien podría aducirse algo similar respecto de las poblaciones inglesas que viven en el continente americano, estas han decidido voluntariamente habitar un territorio bajo administración argentina ${ }^{33}$. Argentina es un país que tradicionalmente se ha viso enriquecido con la migración. Incluso parte de su población desciende de familias que han estado menos tiempo en Argentina que aquellas de las islas.

Las consecuencias legales del tamaño de la población en las islas también ha sido objeto de debate. Se podría argumentar que el número de habitantes no es suficiente para formar una unidad autónoma. Sobre este punto no hay aún acuerdo en el derecho internacional y se ha reconocido el derecho a la libre determinación para grupos reducidos (Franck y Hoffman, 1975: 331-386). Si bien es un factor importante de considerar por sus implicaciones pragmáticas, sentar un precedente sobre el mínimo de habitantes que se requiere para poder invocar el derecho a la libre determinación sería perjudicial para otras comunidades, particularmente en

33 Sobre la inmigración británica en Argentina véase: Bailey, 1979: 539-558; y Jones, 1960: 90-97. los casos en que la población considere que es una comunidad sociopolítica que posee una identidad colectiva. En América Latina hay pueblos indígenas que tienen menos integrantes que la población de las islas ${ }^{34}$. Esto es importante porque algunos derechos de comunidades indígenas del mundo, como el de consulta previa, libre e informada, que son complejos y nacen del derecho a la libre determinación ${ }^{35}$. Si el número de integrantes fuera un parámetro, carecerían de ellos.

El hecho de que se considere que las islas son territorio en proceso de descolonización también conlleva varias consecuencias en el ámbito internacional. De conformidad con el artículo 73 de la Carta de las Naciones Unidas, se debe tener el más alto respeto por los intereses de los habitantes. Es claro que la composición actual de la población no es el resultado de la libre migración sino del poderío militar. Sin embargo, esto es cierto en otras partes del mundo y es un hecho consumado hace casi dos siglos. El derecho a la libre determinación impone a los Estados el deber de poner fin al colonialismo a la brevedad y «teniendo debidamente en cuenta la voluntad libremente expresada de los pueblos a la subyugación que se trate» ${ }^{36}$. Aunque en este caso

34 Como los pueblos Chorote en Argentina o los pueblos Xincas en Guatemala.

35 Convenio 169 de la Organización Internacional del Trabajo sobre Pueblos Indígenas y Tribales en Países Independientes (1989). Arts. 6 y 15.

36 Principios de igualdad de derecho y de la libre determinación, Principio 1, Resolución 2625 (XXV) de la Asamblea General 
no existe una subyugación tradicional, es claro que sí hay injerencia externa en la condición política de los habitantes. Esto no necesariamente implica que el Reino Unido esté obligado a garantizarles de manera unilateral su independencia. En ese caso la potencia europea quedaría al margen de la controversia, como sucedió con Belice, pero subsistiría un diferendo internacional. La libre asociación, la integración a otro Estado y otras formas de organización son formas permisibles bajo el derecho internacional para la descolonización, especialmente en casos en que la autonomía total es inviable. La incorporación a Argentina es permisible, pero solamente si es aceptada por los pobladores. Si se considera que las islas son una colonia, y su inclusión en el Comité Especial de Descolonización apoya esta postura, el Reino Unido deberá necesariamente tomar en cuenta los intereses y decisiones de sus habitantes. A pesar de las críticas argentinas, la libre determinación implica el ejercicio de la autonomía de la voluntad de los pobladores. De lo contrario el Reino Unido incurriría en responsabilidad internacional.

Los posibles efectos de la aplicación del principio de libre determinación al caso de las Malvinas (Falkland) no deben tomarse a la ligera. La Corte Internacional de Justicia ha declarado que es aplicable a todos los territorios no autónomos con arreglo al capítulo XI de la Carta de las Naciones Unidas ${ }^{37}$.

de Naciones Unidas, 24 de Octubre de 1970.

37 Corte Internacional de Justicia. Opinión Consultiva. Consecuencias Jurídicas que
Algunos incluso argumentan que tiene el carácter de ius $\operatorname{cogens}^{38}$. Implica también que incluso si se resolviera finalmente la reclamación territorial sobre las islas entre Argentina y el Reino Unido, ello no significa que el resultado tendría preeminencia sobre los derechos de los habitantes. La libre determinación es un derecho de las personas, no de los Estados y conlleva que puedan tomar decisiones sobre su territorio. La Corte Internacional de Justicia, en el caso de Sahara Oriental, opinó que al resolver diferendos territoriales había que tener presente el derecho a la libre determinación y las reclamaciones de los pobladores ${ }^{39}$. Además, en el caso relativo a Timor Oriental, reconoció el derecho a la libre determinación como principio esencial del derecho internacional, de carácter erga omnes ${ }^{40}$.

tiene para los Estados la Continuación de la Presencia de Sudáfrica en Namibia (África Sudoccidental), no obstante lo dispuesto en la Resolución 276 (1970) del Consejo de Seguridad. I.C.J. Reports (1971) p. 31.

38 Voto disidente del Juez Vicepresidente M. Ammoun p. 90 en Corte Internacional de Justicia. Opinión Consultiva. Consecuencias Jurídicas que tiene para los Estados la Continuación de la Presencia de Sudáfrica en Namibia (África Sudoccidental), no obstante lo dispuesto en la Resolución 276 (1970) del Consejo de Seguridad. I.C.J. Reports (1971).

39 Corte Internacional de Justicia. Opinión Consultiva. Caso Relativo al Sahara Oriental. I.C.J. Reports (1975).

40 Corte Internacional de Justicia. Caso Relativo a Timor Oriental. I.C.J. Reports (1995) p. 29. Véase además, Corte Internacional de Justicia. Accordance with 
Esto no quiere decir que no tenga limitaciones. El derecho se refiere principalmente a limitar la injerencia extranjera y a prohibir la exclusión de sectores de la población basada en criterios raciales o étnicos (Cassese, 2005: 61). Esto no significa que un grupo de la sociedad tenga derecho a que quienes ya están representados por un gobierno puedan llevar a cabo acciones que persigan fraccionar su integridad territorial. No es un derecho de secesión. En el estado actual del derecho internacional los habitantes de un gobierno que garantice sus derechos no tienen facultades para fragmentarlo (Warbrick, 2003: 205). De ahí que en esos casos no se permite que un grupo de la sociedad se independice y pretender establecer su propio Estado.

A manera de conclusión debo resaltar que no hay que subestimar la relevancia de los pobladores de las islas para la solución definitiva del conflicto. La creciente importancia de la persona en el derecho internacional moderno implica que la controversia ya no radica únicamente en Argentina y el Reino Unido; los habitantes de las islas son ahora un tercer actor cuyas consideraciones tendrán substanciales efectos en las reclamos sobre el territorio.

International Law of the Unilateral Declaration of Independence in Respect of Kosovo. Advisory Opinion. I.C.J. Reports (2010) p. 79 y Legal Consequences of the Construction of a Wall in the Occupied Palestinian Territory. Advisory Opinion. I.C.J. Reports (2004) p. 88.

\section{EL PAPEL DE LA COMUNIDAD} INTERNACIONAL Y LOS

\section{BLOQUES REGIONALES}

Más allá de las partes involucradas, los demás Estados también tienen un rol en la resolución de este conflicto. A la comunidad internacional, más que los reclamos territoriales y la determinación sobre cuál bandera ondeará finalmente en sobre las Islas, lo que debe interesarle es que se arribe a una resolución definitiva por medios pacíficos en concordancia con los principios del derecho internacional.Su interés recaerá en evitar un nuevo enfrentamiento armado.

El papel de la comunidad internacional debe de estar dirigido a la promoción del diálogo en aras de buscar una solución pacífica. Las medidas unilaterales, como la explotación de hidrocarburos y otros recursos no renovables en un territorio bajo disputa agregará elementos adicionales que agravan el conflicto. Además generan legítimas preocupaciones ambientales. La militarización de la zona tampoco es prudente, pues eleva las tensiones entre ambos países. Los incidentes que pudieran ocurrir derivados de esto serían aprovechados por los sectores más reaccionarios y aumentan las posibilidades de una nueva confrontación. También, mientras genere pasiones intensas en parte de la población nacional se reducirán los espacios de dialogo y será más difícil la labor diplomática entre Argentina y el Reino Unido (La Nación, 2012).

Es oportuno reconocer también que la posición económica y política de 
Argentina y el Reino Unido ha variado de manera significativa desde la guerra. Argentina es ahora una democracia con un amplio respaldo internacional que contrasta radicalmente con la Junta Militar del siglo pasado. La conformación de un bloque regional suramericano que respalda su postura merece también atención. Las naciones del Mercosur no reconocen a buques que naveguen con las banderas de las Islas, ni se les permite atracar en sus puertos ${ }^{41}$. Aspecto esencial para una explotación viable a gran escala de hidrocarburos en las Islas y para el abastecimiento de su industria. Este tipo de medidas regionales de respaldo a Argentina son relevantes porque evidencian un fuerte apoyo regional que va más allá de las declaraciones simbólicas o de casos curiosos como el de los trabajadores portuarios venezolanos durante la guerra que se rehusaron a descargar whisky escocés en solidaridad con Argentina(Franck, 1983: 115). En el caso del Mercosur, se evidencia un fuerte nivel de compromiso, ya que esta medida costará varios cientos de millones de dólares, entre ellos a la economía de Uruguay que los dejará de percibir en honorarios y pagos asociados por el uso de servicios

41 Declaración de los Estados Partes del Mercosur y Estados Asociados sobre Buques que Enarbolan la Bandera Ilegal de las Islas Malvinas, Montevideo 20 de diciembre de 2011. Adoptada en la XLII Reunión del Consejo del Mercado Común y Cumbre de Presidentes de Mercosur celebrada en Montevideo, Uruguay. portuarios y abastecimiento (Delgado y Castillo, 2011) ${ }^{42}$.

Por la ubicación de las Islas es importante también destacar la influencia que pueda tener ahora Brasil en la controversia. Este país desempeñó un rol significativo durante la guerra. Interceptó a un bombardero inglés y representó a Argentina en las pláticas diplomáticas con el Reino Unido. Su crecimiento económico e influencia en el mundo claramente han aumentado desde 1982. Brasil, que en 1980 no se encontraba entre las diez economías más grandes del mundo, recientemente ha sobrepasado al Reino Unido como la sexta economía mundial (Inman, 2011). Argentina es un socio estratégico de Brasil. Los intercambios comerciales anuales entre ambos países superan los 30 mil millones de dólares. Es una potencia regional y un actor global con interés fundamental en todo lo que ocurre en el Atlántico Sur, en el que posee más de 7,500 km de costa. Por lo que la presencia de la armada inglesa en esa zona no puede escapar su atención. La influencia de los Estados Unidos en la región aún es muy relevante pero ha decaído sustancialmente. Como ejemplo, China es ahora el principal socio comercial externo de Argentina y Brasil (El Economista, 2012). Estos cambios disminuyen la posición del Reino Unido para tomar decisiones unilaterales. Al momento no es previsible un cambio en esta tendencia.

42 Según estima este reportaje Uruguay dejará de percibir desde US\$200 a US\$300 millones anuales. 
Suramérica vive además una explosión económica que contrasta con la actual crisis económica europea. Le será más difícil al Reino Unido obtener el respaldo de sus pares europeos si esto puede afectar la relación de estos con sus socios latinoamericanos. Esto además, porque la controversia por las Islas en sus orígenes proviene precisamente del conflicto entre tres países europeos, y actualmente persiste una controversia similar con España por el control de Gibraltar. De ahí que el Mercosur está mejor alineado para tener una posición uniforme sobre el tema que la Unión Europea.

\section{Conclusión: El Futuro de LAS ISLAS}

El escritor Jorge Luis Borges célebremente calificó la guerra por las Malvinas (Falklands) como «la pelea de dos calvos por un peine» (Álvarez, 2008). La guerra causó pérdidas irreparables, aún permanecen decenas de miles de minas terrestres y no resolvió en definitiva el diferendo.

Si tanto Argentina como el Reino Unido tienen confianza en la legitimidad de sus reclamos sobre las Islas deberían aceptar someter la disputa a un mecanismo de resolución de controversias. Los Estados están obligados a tomar medidas pacificas para la resolución definitiva del conflicto. Sin embargo, por las características particulares de este conflicto, propongo que la disputa es mejor candidata para una solución negociada.
Una solución negociada es conveniente para las partes debido a las circunstancias específicas de esta disputa y en particular por los principios que rigen la descolonización y la libre determinación de los pueblos. De ellos resulta cada vez menos probable que una determinación final sobre el conflicto le otorgue un derecho absoluto sobre las Islas a cualquiera de los dos Estados. Una determinación a favor del Reino Unido en todo caso solamente reafirmaría su obligación de descolonizar. De ahí que la negociación permite a las partes buscar soluciones novedosas con debida consideración a los intereses de todos.

En todo caso la solución deberá tomar en cuenta también los intereses de los habitantes. Esto necesariamente requiere la participación de los isleños y también del Reino Unido mientras reclame derechos sobre las islas ${ }^{43}$. A diferencia de la resolución de un tribunal, la negociación permite adoptar soluciones alternativas. Por ejemplo, si se busca proteger los intereses de los isleños se podría acordar la transferencia de soberanía a Argentina como una región autónoma que provea adecuadas garantías a los habitantes y que les conceda derechos significativos en su administración. Estos derechos incluirían disposiciones especiales sobre na-

43 Si el Reino Unido desiste de cualquier derecho sobre las Islas entonces la controversia sería únicamente entre los habitantes de las Islas y el Estado argentino. Situación similar al diferendo territorial entre Guatemala y Belice. 
cionalidad, lenguaje y administración. Para esto Argentina tiene a su ventaja que es una república federal. Lo que permite que sea una provincia con su propia constitución. También se podría transferir la soberanía con un arrendamiento inmediato (leaseback) por un periodo prolongado a favor del Reino Unido, una opción que han discutido las partes con anterioridad (Reisman, 1983: 317).Otros acuerdos permitirían una explotación sustentable de los recursos con debida consideración a los intereses de todas las partes y medidas apropiadas que resguarden el medio ambiente. Se podría acordar una soberanía compartida sobre ciertos recursos naturales. En todo caso, mientras se arriba a una solución Argentina debería de aprovechar que la cooperación con el continente es vital para el desarrollo de la economía propia de las Islas. Debería de fomentar los intercambios económicos, la cooperación y a la vez demostrar que ya no es la misma región violenta del siglo pasado. Esto ayudará a disminuir la confrontación y a disipar las naturales preocupaciones de los habitantes de las Islas. No puede tratarse el tema de la reclamación territorial sin consideración a aquellos que lo habitan.

Debe reconocerse que la negociación también puede conllevar potenciales desventajas. El tema de las Malvinas (Falklands) tiene un importante papel en la opinión pública de ambos países e históricamente ha encendido la pasión de algunos sectores bajo el escudo del fervor patriótico.Además es posible que algunos interpreten cualquier concesión como una deshonra al sacrificio de los combatientes en la guerra. En algunos casos las autoridades mismas han promovido esta polarización. Por lo tanto limitan su propio campo de dialogo y acción para arribar a una solución negociada.

La lucha por las Malvinas (Falklands) es un tema que genera pasiones que van más allá de su interés geopolítico y valor económico. Una y otra vez en su historia las soluciones pacificas no han llegado porque la clase política se ha dejado guiar por el fervor patriótico nacionalista. La controversia debe de ser resuelta de manera pacífica con base en decisiones racionales guiadas por los principios que inspiran al derecho internacional. A treinta años de la guerra no hay que repetir los mismos errores. La cuestión Malvinas (Falklands) ya se habría solucionado si se hubieran invertido en resolverla, recursos similares a los que se han gastado en perpetuarla.

\section{REFERENCIAS BibliográficAs}

\section{a. Libros:}

Berasategui, Vicente E. (2011), Malvinas. Diplomacia y Conflicto Armado. Comentarios a la Historia Oficial Británica, Proa American Editores.

Boyson, V.F. (1924), The Falkland Islands, Oxford, Clarendon Press.

Cassese, Antonio (2005), International Law, Oxford, Oxford University Press, pp. 61.

Comisión Nacional sobre la Desaparición de Personas (1986), Nunca Más: Informe de la Comisión Nacional sobre la Desaparición de Personas, Buenos Aires, Editorial Universitaria. 
Crawford, James (1979), The creation of States in International Law, Oxford, Clarendon Press, pp. 268.

Dolzer, Rudolph (1993), The territorial status of the Falklands Islands (Malvinas): past o present, Nueva York, Oceana.

Ferrer Vieyra, Enrique (1984), Las Islas Malvinas y el Derecho Internacional, Buenos Aires, Depalma.

Freedman, Lawrence (2005), The Official History of the Falklands Campaign, Routledge.

Freedman, Lawrence y Virginia GambaStonehouse (1992), Señales de guerra: el conflicto de las Islas Malvinas de 1982, Buenos Aires, Javier Vergara.

Goebel, Julius (1950), La pugna por las Islas Malvinas: un estudio de la historia legal y diplomática, New Haven, Yale University Press.

Ian Brownlie, Ian (1999), Principles of Public International Law, Oxford, Oxford University Press, pp. 129-166.

Korman, Sharon (2003), The right of conquest: the acquisition of territory by force in International Law and practice, Oxford, Clarendon Press.

Louis, William Roger y Hedley Bull (eds.) (1986), The Special Relationship: AngloAmerican Relations Since 1945, Oxford, Clarendon Press.

Muñoz Azpiri, José Luis (1966), Historia completa de las Malvinas, Buenos Aires, Oriente.

Palacios, Alfredo Lorenzo (1958), Las Islas Malvinas, Buenos Aires, Claridad.

Pastor Ridruejo, José A. (2009), Curso de Derecho Internacional Público y Organizaciones Internacionales, Madrid, Editorial Tecnos, pp. 618.

Paul, T.V. (1994), Asymmetric Conflicts: War Initiation by weaker powers, Cambridge University Press.

Thatcher, Margaret (1995), The Downing Street years, London, Harper Collins, pp. 173-185.

\section{b. Artículos y capitulos de libros:}

Aizenstatd, Alexander (2011), "Guyana vs. Suriname Arbitral Award» en Rüdiger Wolfrum (ed.), Max Planck Encyclopedia of Public International Law, HeidelbergOxford, Oxford University Press.

Bailey, John P. (1979), «Inmigración y Relaciones Étnicas. Los Ingleses en la Argentina» en Desarrollo Económico, pp. 539-558.

Bolaños, Tania (2009), «Military Intervention without Security Council's Authorisation as a Consequence of the Responsibility to Protect» en Rüdiger Wolfrum and Chie Kojima (eds.), Solidarity: A Structural Principle of International Law. Springer, Heidelberg, pp. 174.

Crawford, James (2001), «The Right to SelfDetermination in International Law: Its Development and Future», en Philip Alston (ed.), Peoples' Rights, Oxford, Oxford University Press, vol. 77, n 1 pp. 7-67.

Franck, Thomas M. (1983), «The strategic role of legal principles in the Falklands War», en American Journal of International Law, vol. 8 pp. 116.

Franck, Thomas M. y Paul Hoffman (1975), «The Right to Self-Determination in Very Small Places» en New York University Journal of International Law and Politics, vol. 40, n ${ }^{\circ} 1$ pp. 331-386.

Jones, Wilbur Devereux (1960), «The Argentine British Colony in the Time of Rosas» en Hispanic American Historical Review, pp. 90-97.

Pickering, Jeffrey y Emizet F. Kisangani (2010), «Diversionary Despots? Comparing Autocracies'Propensities to Use and to Benefit from Military Force», en American Journal of Political Science, pp. 477-493.

Quane, Helen (1998), «The United Nations and the Evolving Right to Self-Determination» en International and Comparative Law Quarterly, vol. 47 n³ pp. 537-572.

Ratner, Steven R. (1996), «Drawing a Better Line: Uti Possidetis and the Borders of New States» en American Journal of International Law, vol. 90, n ${ }^{\circ} 4$ pp. 590-595. 
N. Alexander Aizenstatd • A treinta años de la guerra: las Islas Malvinas...

Reisman, W. Michael (1983), «The Struggle for the Falklands» en Yale Law Journal, vol. $93 \mathrm{n}^{\circ} 2$ pp. 288, 291.

Waibel, Michael (2011), «Falkland Islands/ Islas Malvinas», en Rüdiger Wolfrum (ed.), Max Planck Encyclopedia of Public International Law, Heidelberg-Oxford, Oxford University Press.

Warbrick, Colin (2003), «States and Recognition in International Law» en Malcolm Evans (ed.),International Law, Oxford University Press, pp. 205.

Welch, David A. (1997), "Remember the Falklands? Missed Lessons of a Misunderstood War», en International Journal, pp. 483-507.

\section{c. Referencias informáticas:}

Álvarez, Faustino F., Tiempo de Hoy (2008): Dos calvos y un peine (http://www.tiempodehoy.com/opinion/faustino-f.-alvarez/ dos-calvos-y-un-peine), consultado el $1 \mathrm{de}$ marzo de 2012.

BBC Mundo (2012): El príncipe William llega a Malvinas/Falklands (http:// www.bbc.co.uk/mundo/ultimas_noticias/2012/02/120202_ultnot_llegada_william_malvinas_lav.shtml), consultado el 9 de marzo de 2012.

------ (2012): No talks on Falklands, says Brown (http://news.bbc.co.uk/2/hi/uk_ news/politics/7969463.stm), consultado el 29 de febrero de 2012.

-- (2012): PM acuses Argentina of «colonialism» towards Falklands (http://www. bbc.co.uk/news/uk-politics-16617666), consultado el 23 de febrero de 2012.

Chris Irvine, Chris. The Telegraph (2009): Falklands Islands oil Reserves 'to help British economy' (http://www.telegraph. co.uk/news/worldnews/southamerica/falklandislands/6708902/Falkland-Islandsoil-reserves-to-help-British-economy. html), consultado el 8 de marzo de 2012.

Comité Especial de Descolonización de las Naciones Unidas (2010): Censo hasta el año 2010 (http://www.un.org/es/deco- lonization/nonselfgovterritories.shtml), consultado el 19 de marzo de 2012.

Delgado, E y Castillo, F. El País (2011): Mercosur restringirá barcos de Malvinas(http:// www.elpais.com.uy/111220/pnacio-613731/nacional/mercosur-restringira-barcos-de-malvinas), consultado el 5 de marzo del 2012.

Díaz, Leonel. Prensa Libre (2012): Inglaterra aporta fondos a referendo (http:// www.prensalibre.com/noticias/comunitario/Inglaterra-aporta-fondos-referendo_0_655734451.html), consultado el 1 de marzo de 2012.

El Economista (2012): China, principal socio comercial de Brasil y Chile. (http:// eleconomista.com.mx/economia-global/2012/02/20/china-principal-sociocomercial-brasil-chile), consultado el 2 de marzo del 2012.

El Tribuno (2012): Rechazan las acusaciones de boicot a Gran Bretaña (http://www.eltribuno.info/salta/135314-Rechazan-lasacusaciones-de-boicot-a-Gran-Bretana. note.aspx), consultado el 9 de marzo de 2012.

El Universal (2012): Argentina niega paso a 2 cruceros británicos (http://www.eluniversal.com.mx/internacional/76740.html), consultado el 9 de marzo de 2012.

Goñi, Uki. Time Magazine (2012): Argentina and Britain's Unfinished War: Hate EMail, Harrassing Calls and Prince William (http://www.time.com/time/world/article/0,8599,2106143,00.html), consultado el 8 de febrero de 2012.

Harding, Thomas. The Telegraph (2012): Royal Navy to send HMS Dauntless to Falkland Islands (http://www.telegraph. co.uk/news/newstopics/onthefrontline/9051564/Royal-Navy-to-send-HMSDauntless-to-Falkland-Islands.html), consultado el 8 de marzo de 2012.

Inman, Phillip. The Guardian (2011). Brazil overtakes UK as sixth-largest economy. Phillip Inman. (http://www.guardian. co.uk/business/2011/dec/26/brazil-overtakes-uk-economy), consultado el 22 de febrero del 2012. 
International Law Association, Committe on Aspects of the Law on State Succession (2008): Aspects of the Law of State Succession, Resolution No. 3/2008 (http:// www.ila-hq.org/en/committees/index.cfm/ cid/11), consultado el 8 de abril de 2012. Junta Militar, Comisión de Análisis y Evaluación de las Responsabilidades del Conflicto del Atlántico Sur (1983): Informe Final de la Comisión de Análisis y Evaluación de las Responsabilidades en el Conflicto del Atlántico Sur. (http://www. casarosada.gov.ar/component/content/ article/108-gobierno-informa/25773informe-rattenbach), consultado el 7 de abril de 2012.

Kozloff, Nikolas, The Huffington Post (2012): Falklands Dispute: Argentine Sovereignty Won'tSolvetheProblem (http://www. huffingtonpost.com/nikolas-kozloff/ falklands-dispute-argenti_b_498127. html), consultado el 8 de marzo de 2012.
La Nación (2012): Entrevista con Virginia Gamba (http://www.lanacion.com. ar/1451462-mientras-el-tema-malvinassiga-siendo-una-llaga-abierta-sera-peligroso), consultado el 14 de marzo de 2012.

Ramos Horta, José. Pagina 12 (2012): El Reino Unido debería de dar el ejemplo (http://www.pagina12.com.ar/diario/ elpais/1-187248-2012-02-09.html), consultado el 8 de abril de 2012 .

Romero, Agustín M. Página 12 (2012): La posibilidad de unas islas (http:// www.pagina 12 .com.ar/diario/elpais/1-186150-2012-01-25.html), consultado el 7 de marzo de 2012.

Secretaria de Relaciones Exteriores de Argentina (2012): Posición argentina sobre diversos aspectos de la Cuestión Islas Malvinas (http://www.mrecic.gov.ar/portal/seree/ malvinas/home.html), consultado el 9 de marzo de 2012. 